\title{
Ni absoluta, ni exclusiva. Una reconstrucción de la concepción de la propiedad republicano-jeffersoniana
}

\author{
Neither absolute nor exclusive. A reconstruction of the \\ republican-Jeffersonian conception of property
}

BRU LAÍN*

\begin{abstract}
Resumen: Este texto aborda la concepción de la propiedad republicana-jeffersoniana defendiendo que el principio político-filosófico que subyace a la misma es el del pacto fiduciario. Para ello se define primero la naturaleza de las relaciones fiduciarias que luego se ilustran de acuerdo a dos casos de estudio estrechamente vinculados en el republicanismo de Jefferson: el gobierno político y la propiedad. Se pretende así mostrar que su concepción republicana-fiduciaria es la que alimenta el principio de la "utilidad pública" de la propiedad privada presente todavía hoy en el constitucionalismo democrático.

Palabras clave: propiedad, republicanismo, Jefferson, relación fiduciaria, principal, agente.
\end{abstract}

\begin{abstract}
This paper addresses the Jeffersonianrepublican conception of property by arguing that the political-philosophical principle that underlies it is that of the fiduciary agreement. In order to do so, the nature of fiduciary relationships is firstly defined which are then illustrated through two closely related case studies in Jefferson's republicanism: political government and property ownership. The aim is thus show that his republican-fiduciary rationale is the one that feeds the principle of eminent domain of private property which is still present in democratic constitutionalism.
\end{abstract}

Keywords: ownership, republicanism, Jefferson, fiduciary relationship, principal, agent.

\section{Introducción}

Necesariamente, la vida social implica confianza. En muchas ocasiones, por ejemplo, cuando somos menores de edad o cuando padecemos alguna minusvalía física o intelectual, dependemos de quienes nos rodea para actuar y relacionarnos. En efecto, en la vida social no tenemos más opción que "confiar en los demás para sobrevivir" (Frankel, 2011, 79). Cuando

Recibido: 20/05/2020. Aceptado: 17/06/2020. Cómo citar este articulo: Laín, B. (2020). Ni absoluta, ni exclusiva. Una reconstrucción de la concepción de la propiedad republicano-jeffersoniana. Daimon. Revista Internacional de Filosofía, (81), 99-114. https://doi.org/10.6018/daimon.428761

* Professor asociado, Departamento de Sociología, Universitat de Barcelona (bru.lain@ub.edu). Líneas de investigación: Filosofía política, Sociología económica e histórica, Políticas públicas. Últimas publicaciones: Laín, B. (2020): "Del derecho natural al pacto fiduciario: gobierno y propiedad en la economía política republicana", Isegoría. Revista de Filosofía Moral y Política, Vol. 62, pp. 9-34. Laín, B. (2018): "Comunidades, racionalidad y mercados: una crítica institucional a la defensa emancipadora de la economía colaborativa", Recerca. Revista de Pensament $i$ Anàlisi, Vol. 23, pp. 19-42. Trabajo realizado en el marco del proyecto PGC2018-094324-B-I00 (MCIU/AEI/FEDER, UE). 
esta confianza rebasa los límites de las relaciones más informales, como las de amistad o de parentesco, solemos emplear la institución del contrato. En un contrato legalmente establecido, dos o más partes acuerdan la prestación de un(os) servicio(s) o el intercambio de un(os) bien(es). Es por ello que el derecho privado que regula estos contratos se centra en las normas que estipulan la observancia de los acuerdos establecidos por los mismos. De este modo, la primera función que cumplen tales normas es proveer a las partes de la suficiente seguridad jurídica e institucional de que se cumplirán los deberes y las obligaciones que ambas tienen asignadas contractualmente. Si esto no fuera así, si alguna de las partes incumpliera el cometido asignado -rompiendo así la confianza en ella depositada-, la ley y los tribunales garantizan a la parte damnificada una compensación por los daños o pérdidas en que haya incurrido debido al incumplimiento, por parte de la otra parte, de sus obligaciones contractuales o por haber obrado de mala fe (Sherwin, 2016, 171).

Sin embargo, no todas las relaciones que implican un acuerdo de confianza en el intercambio de bienes o servicios pueden catalogarse como relaciones contractuales. Para lo que aquí interesa, cabe destacar también las relaciones fiduciarias. Una relación fiduciaria es aquella donde una de las partes, debido a su falta de pericia, de tiempo o por cualquier otra restricción, deposita su confianza en la otra para que ésta realice en su nombre un servicio, un deber o cualquier otra tarea. En este sentido, en una relación fiduciaria, "una persona ostenta una autoridad para realizar decisiones discrecionales que afectan a la situación de otra persona [...] donde dicha autoridad es conferida para permitir al concesionario de la misma administrar los asuntos de otra persona" (Smith, L. 2016, 158). Desde este punto de vista, en una relación fiduciaria, "una parte (el fiduciario) ejerce un poder discrecional sobre los intereses prácticos significativos de otra (el beneficiario)" (Miller, 2014, 69).

Son varios los ejemplos que caen dentro de este tipo de relaciones: un doctor y su paciente, un abogado y su cliente o el gestor de una cartera de inversión y sus accionistas. Algunos autores, sin embargo, señalan otros ejemplos más controvertidos como la relación que vincula los gobiernos y los cargos públicos con sus votantes o con la ciudadanía, o la que se establece entre el titular de un bien y quien lo utiliza o explota directamente. En base al derecho fiduciario, este artículo aborda sintéticamente el primer ejemplo -el gobierno y el desempeño de los cargos públicos- para, de este modo, explorar más detalladamente el segundo -los derechos y la institución de la propiedad-. No obstante, para poder abordar estos casos de modo apropiado, se requiere primero detallar con algo más de exactitud la naturaleza de las relaciones fiduciarias en un sentido más genérico.

\section{Obligaciones contractuales; lealtad fiduciaria}

Una estrategia para explorar las relaciones fiduciarias es entenderlas en contraposición a las relaciones contractuales reconocidas por el derecho privado. La característica más distintiva de una relación fiduciaria es que en ella "el fiduciario ejerce una discreción con respecto a un recurso crítico perteneciente al beneficiario", mientras que, en una relación contractual, las partes "ejercen dicha discreción solo con respecto a su propio desempeño bajo el contrato" (Smith, G. 2016, 294). No cabe duda que los deberes u obligaciones emanantes de un contrato y de una relación fiduciaria guardan importantes similitudes pues, par empezar, algunas relaciones fiduciarias pueden ser creadas mediante contrato. Sin embargo, 
lo que en esencia las hace diferentes es que, en ellas, una de las partes siempre ostenta un poder discrecional que afecta a la otra. Este poder es el que precisamente caracteriza este tipo de relaciones y el que, a su vez, puede estar regulado por distintos arreglos jurídicos, como un estatuto o una regulación administrativa, un acuerdo tácito, una relación de estatus o un contrato privado, tal como acabamos de señalar (Smith, L. 2016, 138).

A diferencia del derecho que regula los contratos privados, el derecho fiduciario persigue otros fines. Mientras que el primero sanciona el incumplimiento o la mala fue con que puedan proceder las partes, el segundo tiene por objetivo la observancia del deber de lealtad. Daniel Markovits (2014) propone una lectura ilustrativa de dicha diferencia. En el primer caso, afirma, las partes acuerdan ex-ante el propósito del contrato y los medios para materializarlo de un modo claro, explícito y pautado. Por el contrario, "un fiduciario debe tomar la iniciativa en nombre del beneficiario" y, es justamente por ello que la evaluación de su cometido sólo puede realizarse ex-post, una vez ha ejecutado las funciones que le habían sido encomendadas. Al fin y al cabo, el beneficiario designa a su fiduciario "precisamente porque no puede regular adecuadamente sus propios asuntos". En otras palabras, en una relación fiduciaria "el principal [beneficiario] requiere que su agente [fiduciario] actúe de un modo que no puede especificar ex-ante de forma sustantiva". Mientras que el contrato requiere de la buena fe de la parte contratada en los términos preestablecidos, a un agente fiduciario se le exige principalmente la lealtad y el cuidado de los intereses de su beneficiario o principal, precisamente porque éste le ha depositado su confianza quedando así expuesto a su discrecionalidad. En síntesis, concluye el autor, puede decirse "que el beneficiario compra la iniciativa de su fiduciario" (Markovits, 2014, 215).

Paul B. Miller $(2014,72)$ destaca las tres propiedades estructurales que definen una relación fiduciaria: i) la "desigualdad" en favor del fiduciario en el ejercicio de su poder; ii) la "dependencia" de los intereses prácticos del principal o beneficiario a la lealtad de su agente fiduciario; y iii) la "vulnerabilidad" en que se halla el primero respecto al potencial mal uso de la confianza que ha depositado en el segundo. Consecuentemente, una relación fiduciaria es potencialmente conflictiva, pues siempre implica un "cierto riesgo" para el principal (Frankel, 2011, 25) que, de este modo, tiene que cargar con lo que los sociólogos llaman "costes de agencia"' . En este sentido, defiende Miller $(2014,73)$, el poder del agente fiduciario adopta cuatro características: i) es un poder "discrecional", pues tiene que disponer de libertad en el ejercicio de las funciones encomendadas - por bien que dicha libertad no es irrestricta; ii) es un poder "específico", pues ha sido conferido por un fin concreto y no por otros; iii) es un poder "relacional", puesto que el fiduciario no es soberano sino que su autoridad emana de la personalidad jurídica de su beneficiario o principal; y iv) es un poder conferido en virtud de la protección de unos "intereses prácticos específicos" asociados al cuidado del bienestar, de las propiedades o de la misma personalidad jurídica del principal o beneficiario. Por todo ello, y dada la gran discrecionalidad con que los agentes fiduciarios deben poder ejercer su poder, "el deber de lealtad requiere que el fiduciario demuestre fidelidad a los propósitos de su mandato" (Miller, 2018, 43).

1 Los problemas de agencia incluyen, por ejemplo, los costes de información, oportunidad o control a los que debe hacer frente el principal que suelen emerger cuando "una persona, el principal, involucra otra persona, el agente, en la realización de acciones discrecionales imperfectamente observables que afectan al bienestar del principal" (Sitkoff, 2014, 198). 
Hasta aquí hemos tratado sucintamente las características que definen la naturaleza de las relaciones fiduciarias entendidas, como en el caso de los contratos, desde la óptica del derecho privado. Sin embargo, varios autores defienden la pertinencia de entender las relaciones fiduciarias también y, sobre todo, desde la óptica del derecho público ${ }^{2}$. Es aquí donde el caso de las instituciones políticas, del gobierno o del estado suelen invocarse como ejemplos pues, a fin de cuentas, "la idea de que los cargos y las instituciones públicas sirven como fiduciarios goza de un respetado pedigrí en la teoría legal y política" (Criddle y Fox-Decent, 2018, 70). Nótese que el mecanismo representativo mediante el que opera un gobierno es difícil de conceptualizar en base a la lógica privada-contractual definida anteriormente. Esto se debe, sobre todo, a que los ciudadanos no pueden determinar ex-ante el modo preciso en que aquél ejecutará sus funciones políticas. La acción de gobierno no puede materializarse sino mediante una cierta discrecionalidad en base a la confianza en él depositada y observando siempre la lealtad para con sus constituyentes. Dicho en las palabras antes empleadas, se puede afirmar que la ciudadanía-principal "compra la iniciativa de su fiduciario" o gobierno. No disponemos del espacio necesario para discutir la relación entre el derecho privado y el público a la hora de entender las instituciones políticas cual agentes fiduciarios ${ }^{3}$. Lo cierto, no obstante, es que "el proyecto del gobierno fiduciario reconoce que el derecho público y el privado tienen mucho que aprender el uno del otro" (Rave, 2018, 49).

\section{El gobierno como agente fiduciario: de Cicerón a los founders}

Aunque en la actualidad "el lenguaje de la cosa pública como fiduciario o trustee ha sido casi olvidado" (Finn, 2012, 33), el derecho fiduciario aplicado al estado o al gobierno tiene un largo recorrido histórico. Tamar Frankel (2011, 80-96) señala que desde el código hammurabi de la antigua Mesopotamia, pasando por el Nuevo Testamento o hasta la ley islámica de la Sharia, entre otros códigos legales, contienen una gran cantidad de formas jurídicas que reconocían y regulaban los derechos y los deberes de las distintas figuras que componen las relaciones fiduciarias. De hecho, "la idea de que el gobierno ostenta su poder como fideicomiso [trust] para con la gente se remonta a Aristóteles, Cicerón y a la República

2 En este sentido, puede consultarse: Evan Fox-Decent (2011; 2014); Paul B. Miller (2014); Ethan J. Leib, David L. Ponet y Michael Serota (2014) y D. Theodore Rave (2013) quienes defienden las implicaciones fiduciarias de ejercer la autoridad política y el servicio público; Evan J. Criddle (2014) y Evan Fox-Decent y Evan J. Criddle (2009) que defienden una lectura fiduciaria del derecho internacional y de los derechos humanos respectivamente; Robert G. Natelson (2004) quien aboga por una interpretación fiduciaria de las cartas constitucionales; o Ken Coghill, Charles Sampford y Tim Smith (2012) quienes realizan una lectura fiduciaria de las obligaciones públicas para con el cambio climático. Así mismo, Irit Samet (2014) defiende una lectura fiduciaria de la virtud kantiana; mientras que Steven Vaitkus (1991) realiza una interpretación fiduciaria de las relaciones inter-subjetivas que constituyen la sociedad misma. La crítica a la concepción fiduciaria del derecho público, puede hallarse en Ethan J. Leib y Stephen R. Galoob (2016); Jedediah Purdy y Kimberly Fielding (2007), o D. Theodore Rave (2018).

3 Sirva lo siguiente únicamente como nota introductoria a dicha controversia: los críticos a la lectura del derecho público fiduciario suelen objetar que los cargos e instituciones públicas no puden ser consideradas como fiduciarios. Éstos, "a diferencia de un fiduciario privado, hallan múltiples problemas de lealtad que son insalvables e intrínsecos a sus roles públicos" (Criddle y Fox-Decent, 2018, 67), pues el poder legislativo, a menudo debe velar por los intereses de diferentes constituyentes que, no en pocas ocasiones, son divergentes y encontrados. 
de Platón" (Frankel, 2011, 280). No en vano, "el concepto legal del fideicomiso proviene de los tiempos de la antigua Roma" (Fox-Decent, 2011, 30).

Dentro del republicanismo clásico, fue Marco Tulio Cicerón quien mejor señaló la naturaleza fiduciaria de la institución política y, por ello, de la vocación de lealtad y fidelidad [fidei suae commisa] con que debe obrar quien ocupa un cargo en ella. "Así pues", defiende en De Officis, "la obligación propia del magistrado es entender que representa a la ciudad [...] y tener presente que todo esto ha sido encomendado a su fidelidad" (Cicerón, 1948, I, XXXIV, 113). En particular, en su defensa del gobierno y del cargo público como agente fiduciario o comisariado, emplea el término "tutela" -la tarea de administrar aquello o aquél que carece de personalidad jurídica propia, como un menor de edad-, en un sentido metafórico con una fuerte carga política:

Aquellos que han de estar al frente del gobierno, tengan muy presentes los dos preceptos de Platón: uno, que de tal manera velen por la utilidad de los ciudadanos [tueantur], que, olvidados de la suya propia, todo cuanto hagan lo refieran a dicha utilidad común. El otro, que cuiden de todo el cuerpo de la república, de manera que, mientras atienden [tuentur] a alguna parte no desamparen las demás; porque, así como la tutela así también el gobierno de la república debe desempeñarse para utilidad de aquellos que han sido encomendados [qui commissi sunt] y no para la de aquellos a quienes fueron encomendados [quibus commissa est]. Por consiguiente, quienes atienden a una parte de los ciudadanos y descuidan otra, introducen, en contra de la ciudad, una cosa muy perniciosa, a saber, la sedición y la discordia (Cicerón, 1948, I, XXV, 85).

De acuerdo a estas dos citas de Cicerón, pueden extraerse varias conclusiones:

i) que importantes figuras del derecho privado y del derecho público -por lo pronto, la de la "tutela" y del "gobierno", respectivamente- se hallan estrechamente imbricadas en los fundamentos de la teoría política clásica que, como veremos a continuación, impregnarán la filosofía política republicana del mundo moderno ${ }^{4}$;

ii) que el cargo de magistrado debe ejercerse exclusivamente con arreglo a la "utilidad común", esto es, con el único objetivo del cuidado del cuerpo político todo y no de una parte, pues ello conlleva inexorablemente a la "sedición y la discordia" y que,

iii) en consecuencia, el ejercicio del cargo del magistrado (fiduciario) no puede ser otro que la obligada y recta observancia de la lealtad que éste debe a los ciudadanos (fideicomitentes), en cuya "fidelidad" descansa la naturaleza y la razón de su cargo.

4 Este concepto de "tutela" añade cierta de complejidad a la estructura fiduciaria que tratamos de explicar. Desde el punto de vista jurídico, un menor objeto de tutela no pude ser considerado fideicomitente sino beneficiario de su tutor, pues es su falta de agencia y personalidad jurídica lo que lo inhabilita para ordenar el encargo o consentir al segundo la tutela sobre sí mismo. Para Cicerón, la tutela que ejercen los magistrados, no implica tratar a todos los ciudadanos como fideicomitentes sino más bien como menores de edad y, por ello, meros beneficiarios de sus tutores políticos. La metáfora ciceroniana, aunque útil para nuestros propósitos expositivos, revela la perspectiva aristocrática y antidemocrática del romano y deja entrever la lógica paternalista con que entendía el gobierno sobre la mayoría de la ciudadanía pobre. 
La lógica que subyace a la argumentación ciceroniana entronca directamente con la filosofía y la ciencia política del mundo moderno, en particular, con la del republicanismo norteamericano. No cabe duda de que "la metáfora fiduciaria aparece ubicada justo después de la de 'libertad' y de 'republicanismo' como un elemento de la ideología del momento" (Natelson, 2004, 1086). Ávidos lectores de los clásicos, en especial de Cicerón (Wood, 2011, 13), para los revolucionarios americanos la relación fiduciaria más genuina era "la que existe entre la comunidad (el pueblo) y el Estado" (Finn, 2012, 31). De este modo, "la filosofía política americana considera que la relación entre el pueblo y el gobierno da al segundo la libertad de actuar en nombre [...] del pueblo. La persona en un cargo emplea su libertad para actuar por sí misma -tomando la iniciativa o haciéndose cargo- con el fin de actuar en nombre del pueblo" (Mansfield, 2003, 27).

Esta "filosofía política americana" imperó durante todo el periodo fundacional, tal como lo atestigua la famosa Declaration of Rights de Pennsylvania de 1776, de acuerdo a la cual, "todos los poderes [...] derivan del pueblo: por lo que todos los cargos del Gobierno, sean del legislativo o del ejecutivo, son sus fiduciarios [trustees] y sirvientes y siempre responsables ante él" (Finn, 2012, 32). Existen, así mismo, muchos otros textos que prueban la naturaleza fiduciaria en que, para el republicanismo norteamericano, debía fundarse su gobierno. Uno de las más conocidos se halla en el número 46 del The Federalist escrito por James Madison en un inconfundible estilo ciceroniano: "el gobierno federal y los de los estados no son sino diferentes agentes y fiduciarios del pueblo" (Madison, 2001, 243). Otros founders lo expresarían de un modo todavía más contundente. Para Thomas Jefferson, por ejemplo, debía dejarse a los ciudadanos "ocuparse de todo aquello que estuviera dentro de su alcance y sus competencias, y dejar el resto a sus representantes, elegidos inmediatamente y deponibles por ellos mismos". Esta es, precisamente, la "característica que constituye la esencia de una república" (Appleby y Ball, 1999, 293). La inexorable consecuencia de esta argumentación no deja lugar a dudas: cuando los agentes o trustees depositarios de la confianza del pueblo traicionan la lealtad en ellos depositada, se convierten en déspotas. Luego, aquellos pueden y deben deponerlos sin dilación. Así lo expresaría en 1774 en su $A$ Summary View of the Rights of British America:

Cuando el cuerpo representativo ha perdido la confianza de sus constituyentes, cuando infamemente ha vendido sus derechos más valiosos, cuando ha asumido poderes que el pueblo nunca depositó en sus manos, entonces ciertamente su permanencia en el cargo se convierte peligroso para el estado, y requiere el ejercicio del poder de disolución (Appleby y Ball, 1999, 76).

Para el republicanismo jeffersoniano contenido en la Declaración de Independencia de 1776, existen ciertos derechos naturales, evidentes e inalienables -“a la vida, a la libertad y a la búsqueda de la felicidad"- para cuya materialización e institucionalización se requiere, o bien el concurso directo de sus justos depositarios - "todos los hombres creados igual"-, o bien, y lo que es más factible en sociedad, la designación de unos representantes fiduciarios cuyos "justos poderes derivan del consentimiento" de los primeros. Es justamente por ello que, "cuando cualquier forma de gobierno se vuelve destructiva a estos fines, es el derecho del pueblo alterarlo o abolirlo, e instituir un nuevo gobierno", sentencia la Declaración. Es 
por ello que este consentimiento -la delegación del cuidado de los derechos naturales- es siempre limitada, temporal y revocable por parte del pueblo, principal o fideicomitente.

La concepción republicana-jeffersoniana de la naturaleza del ejercicio del poder político parte, de este modo, de la idea que el estado "no es sino la encarnación de la soberanía popular, la cual es la idea de que el poder político proviene del pueblo y, por lo tanto, que los funcionarios públicos son los agentes fiduciarios del pueblo" o, de un modo más sintético, "que el estado es el fiduciario del pueblo [principal] sobre el cual ejerce poder" (Fox-Decent, 2011, 170 y 3). Como persuasivamente señala Evan J. Criddle, "la contribución más importante de la teoría republicana puede ser el hecho de situar el derecho fiduciario dentro de una rica explicación filosófica que pone en relación las instituciones públicas, las relaciones privadas, y el derecho privado". A su vez, esta relación todavía hoy identificable en el derecho fiduciario americano, "refleja el compromiso normativo del republicanismo con la idea de la libertad como no dominación" (Criddle, 2017, 1024-25).

Hasta aquí hemos tratado sucintamente la naturaleza fiduciaria que para el pensamiento republicano (desde Cicerón hasta Jefferson) encarna la institución del gobierno político. Este era el primer ejemplo de relación fiduciaria que anunciamos al inicio de este texto. El segundo era el de la propiedad. En lo que sigue pues, nos ocuparemos a estudiar la naturaleza y la importancia que el republicanismo confirió a la propiedad y su concepción como una institución fiduciaria. Se pretende poner así de relieve dos cuestiones cruciales para el derecho y la filosofía política: por un lado, que es muy cuestionable que la propiedad descanse sobre un supuesto derecho individual de carácter "exclusivo y despótico" y, por el otro, que la naturaleza fiduciaria que el republicanismo imputó a la institución y al derecho de propiedad puede (y debe) rastrearse en el constitucionalismo moderno.

\section{Libertad, dominación, propiedad}

Como han mostrado varios autores, el ideal de la libertad como no dominación es distintivo del pensamiento republicano en el sentido en que este, a diferencia del liberalismo político, establece que uno no es libre si puede ser dominado por otro(s), esto es, si su situación de dependencia, vulnerabilidad o subalternidad lo vuelve potencialmente interferible por la voluntad, el deseo o el capricho arbitrario de un tercero. Es por esta razón que el republicanismo siempre entendió la propiedad como una condición necesaria para la consecución de la libertad. Solo quien disponga de propiedad suficiente -quien sea materialmente independiente- podrá vivir y relacionarse de forma libre y autónoma, pues uno solamente puede ser libre "si es capaz de actuar bajo iniciativa propia". Depender de otro "sea tirano o patrón, señor o benefactor, implica no ser libre". La libertad exige así "ser materialmente independiente para no tener que confiar en otros para el sustento, ni estar obligado a pedir ni aceptar favores". En síntesis: "la garantía de la propiedad es esencial para disfrutar la libertad republicana" (MacGilvray, 2011, 28-9). De aquí que, entender la naturaleza del gobierno republicano en sentido fiduciario, exija abordar el significado que para el republicanismo tiene la cuestión de la propiedad.

La historia juega un papel fundamental "en la construcción de las características formales del derecho" (Sherwin, 2016, 167), por lo que es en ella donde debemos fijarnos para comprender el significado de la propiedad que ha heredado el mundo contemporáneo. Es en este sentido que el norteamericano emerge como un caso de 
estudio de obligada referencia. No en vano, es famosa allí la expresión del congresista virginiano, Arthur Lee $(1775,14)$, quien pomposamente dejó dicho que "la propiedad es la guardia de todos los demás derechos", por lo que, "privar un pueblo de ella, es privarle de su propia libertad". Dada la importancia que suscita el caso americano, esta sección desarrollará una explicación de la concepción republicana de la propiedad que allí se desarrolló y que, a diferencia del grueso de la filosofía política y jurídica contemporánea, pondrá de relieve la lógica fiduciaria que subyace a dicho concepto. Así como la Revolución americana (junto con la francesa) es leída a menudo como el ejemplo paradigmático de "revolución burguesa" y punto de arranque del "moderno liberalismo político" (Hartz, 1995); así también la concepción de la propiedad que allí se articuló ha tendido a explicarse en base a la idea de una supuesta "propiedad liberal clásica" (Whelan, 1980, 102). Uno de los problemas de dicha interpretación parte de considerar el de propiedad como un derecho individual de carácter exclusivo y excluyente cuando, en realidad, se halla siempre "sujeta y fragmentada entre mucha gente en una gran variedad de formas" (Clarry, 2014: 903).

Esta noción de la "propiedad liberal" suele basarse en la definición del jurista inglés, William Blackstone de 1765, para quien la propiedad era "aquel dominio exclusivo y despótico que un hombre reclama y ejerce sobre las cosas externas del mundo, en total exclusión del derecho de cualquier otro individuo en el universo" (Blackstone, 1897, 167). La fórmula del "dominio exclusivo y despótico" será retomada por del Código Civil napoleónico de 1804, que volvía a sancionar la propiedad como "el derecho a gozar y disponer de las cosas de la manera más absoluta" (art. 544). El pensamiento libertariano de raíz anglosajona dominante hoy en el mundo académico ha hecho suya esta noción de la "propiedad liberal clásica", haciendo hincapié en que el derecho de propiedad debe entenderse en un doble sentido: i) el derecho a usar (ius utendi) y obtener beneficios de un recurso (ius fruendi), y ii) el derecho a disponer del mismo (ius abutendi) y a enajenarlo de forma irrestricta (Lewis, 1985; Godden, Grinlinton y Taylor, 2011; Sheehan y Small, 2002). Para esta interpretación, el derecho individual de exclusión "es un elemento fundamental del derecho de propiedad" (Callies y Breemer, 2000, 40) y tan "implícito en la concepción básica de la propiedad privada" (Epstein, 1985, 63), que "abolirlo resultaría una ofensa para el propio derecho" (Laitos, 1998, 17). De aquí que finalmente se proclame el "triunfo de la "propiedad moderna" y su superioridad como una forma jurídica "exclusiva, libre, absoluta, [y] perfecta” (Congost, 2003, 76).

Al sobre enfatizar estos tres derechos -el de libre y exclusivamente usar, beneficiarse y enajenar un recurso-, el grueso de la filosofía contemporánea ha tendido a adoptar de forma acrítica la noción blackstoniana como el "control irrestricto y exclusivo que una persona ostenta sobre una cosa" (Lewis, 1985: 241) y, del mismo modo, a imputar su más genuino desarrollo jurídico y filosófico en la historia norteamericana. Sin embargo, es paradójico el modo en cómo esto ya fue refutado por uno de los más destacados representantes del pensamiento americano fundacional, Thomas Jefferson, quien en 1810 dejaría dicho:

[...] lamento la degradación de la ciencia jurídica. La opinión parece ser que Blackstone es para nosotros lo que el Alcorán es para los mahometanos, que todo lo que es necesario está en él, y que lo que no está en él no es necesario. [El libro de 
Blackstone] No es más que un elegante resumen de lo que se habrá adquirido de las verdaderas fuentes del derecho (Appleby y Ball, 1999, 182).

Nada más que un "elegante resumen”, en el mejor de los casos, o una "degradación de la ciencia jurídica", en el peor. Así de contundente calificaba el de Virginia la obra del jurista inglés. Mas, si para el republicanismo, el de propiedad no es un derecho exclusivo ni despótico, ¿cuál es entonces su naturaleza y cuáles sus diferencias con respecto a la "propiedad liberal clásica”?

\section{La concepción (fiduciaria) de la propiedad en el republicanismo jeffersoniano}

El derecho de propiedad, particularmente sobre la tierra, fue siempre "fundamental y parte de la preservación de la libertad en los Estados Unidos" (Callies y Breemer, 2000, 39). Por eso jugó siempre un papel central tanto en su filosofía como en los distintos textos constitucionales, aunque, como ya indicamos, nunca se reconociera como el dominio absoluto blackstoniano. Derivada del principio de la "utilidad pública" y del de "no molestia" (nuisance) provenientes del derecho romano y de la common law inglesa, las colonias primero y luego los Estados promulgaron una gran cantidad de regulaciones que, desde la fundación hasta pasada la guerra civil, limitaron enormemente la naturaleza y el alcance de los derechos de los propietarios particulares. Así lo atestigua la Constitución de Vermont de 1777 (Cap. I, Art. II), según la cual, "la propiedad privada debe servir al uso público cuando la necesidad así lo requiere".

Aunque no exento de contradicciones, el republicanismo norteamericano justificó así la regulación y la limitación de la propiedad privada sobre importantes aspectos de la vida económica. Por ejemplo, sobre los bienes de consumo como la harina, el pan o el alcohol al limitar su precio y las tarifas en su comercio, sobre las propiedades inmobiliarias restringiendo la construcción de edificios para no afectar a inmuebles colindantes, sobre el uso de los campos, ríos, lagos o acuíferos privados al permitir la caza o la pesca de terceros, e incluso sobre los préstamos, cuyo interés se limitó al 6\% en la mayoría de territorios. Así mismo, tampoco se permitía el uso irrestricto sobre otra de las más importantes propiedades, los esclavos, prohibiendo su ejecución o maltrato físico u obligando a sus propietarios a alimentarlos, calzarlos o vestirlos adecuadamente (Lynd, 1969, 106). Estas prácticas regulacionistas de mediados del siglo XVII se extendieron hasta mucho después, tal como lo ilustra las palabras escitas en 1851 por el juez de Massachusetts, Lemuel Shaw:

Toda propiedad en esta república [...] está sujeta a aquellas regulaciones generales que son necesarias al bien común y al bienestar general. Los derechos de propiedad, como cualquier otro derecho social y convencional, se hallan sujetos a dichas razonables limitaciones en su uso para prevenir que puedan ser usados de modo injurioso (Ely, 1992, 61). 
Hasta el segundo tercio del siglo XVIII, por lo menos en teoría, ningún colono ostentaba el dominio absoluto sobre sus tierras puesto que su posesión dependía de su previa concesión por parte de la Corona. Dichas concesiones se hallaban condicionadas a un sinfín de obligaciones políticas y económicas, la más común de las cuales era la quitrent o el pago anual a la Corona o al lord particular. Esta forma de arrendamiento tuvo que convivir con otras formas de posesión de la tierra idiosincráticas de un vasto territorio todavía por colonizar. Una de estas formas era el llamado headright o la concesión de hasta 50 acres de tierra a todo colono que quisiera establecerse concedidas por las agrupaciones municipales, por ejemplo, las de Virginia o Carolina del Norte, en cuyo caso se llegaban a ofrecer hasta 150 acres. Fundado en la lógica de la "utilidad pública" ya mencionada, este fue uno de los mayores mecanismos de redistribución de la tierra durante el periodo fundacional que, así mismo, tuvo una importante trascendencia en el pensamiento republicano de entonces y que se extendió hasta finales del siglo XIX con leyes como el Homestead Act aprobada por el Congreso en 1861 .

Sin embargo, el rápido desarrollo económico y agrario experimentado a lo largo del siglo XVIII favoreció la aparición de grandes desigualdades económicas y, por ello, de una rápida escalada de la conflictividad social. Un ejemplo fueron las tensiones provocadas por la emergencia de grandes monopolios de tierras propiciados por la acumulación de headrights. Desde antes de la independencia, muchas de las colonias como Massachusetts, Maryland o Virginia, regularon o directamente prohibieron estas formas de tenencia de la tierra, sobre todo cuando ésta no se cultivaba y simplemente se empleaba para especular. La doctrina de la "utilidad pública" fundada a su vez en la tradición del derecho natural, llevará al mismo Jefferson, y con él al grueso del republicanismo, a censurar esta práctica monopolística y especulativa: "Cuando hay en este país tierras sin cultivar y gente pobre desempleada, no cabe duda de que las leyes de la propiedad se han extendido tanto como para violar el derecho natural. La tierra ha sido concedida como un recurso común para que el hombre la trabaje y viva en ella" (Ford, VIII, 196).

Partiendo del propietarismo republicano clásico y del ideal del "cristianismo pastoril" (Richard, 1994, 159), Jefferson apelaba al derecho natural, en particular a su "violación", cuando la tierra servía a fines meramente especulativos. Si bien la tierra ha sido concedida "como un recurso común", el derecho de propiedad sobre la misma no se sustenta sobre el derecho natural, recalcaba. Existe, sin duda, un derecho natural individual a ocupar, trabajar y a apropiarse de aquello que se ha producido con las propias manos (Antieau, 1960, 65). En un claro estilo lockeano (Lynd, 1969, 18-24), el derecho natural respaldaba la apropiación natural de aquello necesario para sobrevivir, pero con "una importante limitación a estos derechos", pues nadie puede emplearlos "para obstruir el disfrute de los mismos derechos de los otros" (Jefferson, 1812, 61). En síntesis, las limitaciones republicano-jeffersonianas "sobre el ejercicio de los derechos naturales implicaban: 1) el considerar el bien común y 2) el respeto de los mismos derechos de los otros" (Antieau, 1960, 52). No existe pues un derecho natural que justifique la acumulación irrestricta de tierras, ni acaso su dominio absoluto, pues

[...] sería singular admitir un derecho natural y aun hereditario [sobre ella]. [...] ningún individuo posee, como derecho natural, una propiedad separada en un acre de tierra, por ejemplo. Por ley universal, en efecto, sea fija o móvil, pertenece por igual 
a todos los hombres en común, es la propiedad de aquél durante el momento en que la ocupa, pero cuando aquél la abandona, la propiedad va de consuno. La propiedad estable es el regalo de la ley social, y es dada por el progreso de la sociedad (Appleby y Ball, 1999, 579-80).

El derecho sobre la tierra se circunscribe "durante el momento" en que se ocupa y únicamente se justifica por su uso productivo. La tierra pertenece "por igual a todos los hombres en común" y son ellos quienes, mediante el "regalo de la ley social" confieren a los particulares el derecho a "usufructuarla" (Ford, V, 342) con el fin último del "progreso de la sociedad". Como acabamos de ver, la propiedad individual no se sustenta sobre el derecho natural, pues ninguna sociedad "ha reconocido un derecho de propiedad sobre tierras cedido totalmente a los individuos". Es más:

El gobierno debe establecerse, y deben aprobarse leyes, antes de que las tierras puedan ser apropiadas separadamente, y el propietario protegido en su posesión. Hasta entonces la propiedad se encuentra en el cuerpo de la nación, y ellos, o su jefe, cual fiduciario [trustee], debe garantizársela a sus ciudadanos, y determinar las condiciones de las concesiones (Jefferson, 1812, 31).

Jefferson empleará la argumentación fiduciaria, no solo para justificar el derecho de propiedad sobre la tierra, sino también para determinar de qué modo puede distribuirse y ser apropiada por los individuos. Primero debe establecerse un gobierno y unas leyes, pues sin la ley civil no puede existir el derecho de propiedad. Es luego cuando el "cuerpo de la nación" puede, o bien administrarla directamente, o bien, y lo que le parece más factible en sociedad, delegar a su "jefe" o gobierno "cual fiduciario" el modo en que debe ser "garantizada" y "concedida" a los ciudadanos. Puede concluirse así que, para la teoría republican-jeffersoniana,

[...] la propiedad de cualquier recurso o activo (especialmente de tierra) es pública, y lo que llamamos 'propiedad privada' no es sino la apropiación privada del recurso en cuestión como un fideicomiso público en una relación Principal/Agente: el propietario particular [...] es simplemente un fiduciario de la propiedad pública o soberana. El soberano (el monarca o el pueblo) es el Principal ('trustor') y el propietario es el Agente ('trustee') en una relación social llamada propiedad (Domènech y Bertomeu, 2015: 6-7).

Sin embargo, el término "propiedad pública" empleado aquí no se refiere a la de titularidad estatal, sino a aquella que pertenece al común de todo el pueblo soberano. La propiedad fiduciaria no se circunscribe únicamente a aquella regimentada por el pacto entre el Pueblo soberano y sus trustees particulares, sino también entre el primero y el mismo gobierno o estado. En otras palabras, para el republicanismo jeffersoniano, tanto la propiedad privada particular como la pública-estatal no son sino dos arreglos institucionales distintos igualmente conceptualizados dentro de la misma lógica fiduciaria. Así, tanto el particular como el gobierno no son sino dos tipos de trustees o agentes fiduciarios depositarios de la confianza 
de, y por ello subordinados, al "interés general" del soberano. A su vez, ambos arreglos institucionales vienen informados por la doctrina del derecho natural que, por un lado, habilita a los particulares y al gobierno a poseer y usar la tierra pero que, al mismo tiempo, limita el uso que de estos derechos pueden hacer.

En este sentido, cabe destacar una de dichas limitaciones, quizás la más importante: el eminent domain o el principio de la "utilidad pública" de la propiedad privada. Esta limitación toma su forma jurídica a través de un largo recorrido histórico, pero adopta su forma jurídica moderna durante la experiencia norteamericana. El eminent domain es el poder que el soberano confiere fiduciariamente al gobierno para que éste obligue a un particular (individuo o empresa) a transferirle una o varias de sus propiedades bajo la justificación de la utilidad pública y sin contar con su consentimiento. La fórmula del eminent domain es especialmente interesante aquí al ilustrar de un modo muy informativo la naturaleza fiduciaria de la propiedad republicana.

Durante la época colonial y hasta después de la guerra civil, las cortes estatales llegaron a delegar el ejercicio de este poder, no solo a las legislaturas, sino también a los propietarios particulares. Así, por ejemplo, un molinero podía inundar parcialmente las tierras adyacentes de otro particular para ampliar el caudal necesario para su actividad. Como compensación, el primero debía indemnizar al segundo, pero ello no cuestionaba el poder legal que los tribunales habían concedido al primero puesto que se entendía que el ejercicio de dicho poder revertía en el bienestar público. Por otro lado, y desde 1748, las leyes y los tribunales también autorizaban a las herrerías a tomar cierta parte de la madera y a abrir caminos en los bosques de otros particulares para fomentar la producción y el comercio de hierro. Estas compañías, a pesar de ser negocios privados, suponían un beneficio para la comunidad y eran vistas como un tipo de servicio público, por lo que "se consideraba apropiado que dichas empresas poseyeran las ventajas del eminent domain" (Ely, 1992, 24).

La interpretación jurídica y la aplicación política del eminent domain limitaron los derechos y el uso de la propiedad privada en varios sentidos. Por un lado, las cortes estatales emplearon una definición muy extensiva del principio de la "utilidad pública" y confirieron su ejercicio a las legislaturas estatales quienes, como se ha señalado, podían delegarlo fiduciariamente a las compañías privadas o a los particulares en provecho del bienestar público. Por el otro lado, las legislaturas coloniales y después las estatales hicieron un uso muy restrictivo del significado de "expropiación" con el fin de limitar el coste de las compensaciones. De este modo, se potenciaba el desarrollo del comercio, el transporte y la manufactura a un coste muy reducido para las maltrechas arcas públicas, y se establecía así mismo un mecanismo para que ciertos particulares contribuyeran a subsidiar las obras y las infraestructuras públicas.

Cabe añadir que, si bien la compensación a pagar por las expropiaciones era una práctica extendida que los particulares podían reclamar como un derecho moral, en ningún caso constituía un derecho formal y, por tanto, no lo podían exigir legalmente. No fue hasta 1791 que, con la Quinta enmienda incluida en la Bill of Rights, se introdujo el derecho de la "justa compensación" y la taking clause, bajo las cuales el Gobierno federal quedaba obligado a indemnizar a los particulares. Sin embargo, ello no ponía en cuestión que, tanto la propiedad de las personas físicas como la de las compañías privadas, seguían subordinadas al "interés público", incluso cuando ello suponía la alteración o la extinción 
de contratos mercantiles y comerciales preexistentes (Ely, 1992, 70-71). Aún así, hizo falta más de un siglo y -parafraseando a Hobsbawm- transitar la "era de la revolución", para que el principio de la "utilidad pública" o del eminent domain se incorporase plenamente en el constitucionalismo moderno y democrático.

\section{Conclusión}

Este artículo ha mostrado que la noción de propiedad que comúnmente se emplea parte de una interpretación sesgada en cuanto a su desarrollo jurídico e histórico. Para ello, hemos confrontado la idea del derecho individual exclusivo y excluyente con la de la propiedad republicano-fiduciaria. Con tal objetivo, hemos empezado argumentando que no todas las relaciones que requieren de un acuerdo de confianza pueden catalogarse como relaciones contractuales. Para ilustrar esta discusión, hemos analizado dos casos paradigmáticos dentro de la filosofía política y del derecho: el de los gobiernos y los estados, por un lado, y el de la institución y los derechos de propiedad, por el otro.

Para abordar estos dos casos de estudio, nos hemos fijado en la tradición republicana norteamericana encabezada por Thomas Jefferson para la cual, tanto los representantes políticos como los propietarios (tanto los particulares como el estado), no son sino agentes fiduciarios de lo que por derecho natural pertenece a cada miembro del común: la libertad y la soberanía política y la posesión de los recursos naturales, respectivamente. En cuanto al primer ejemplo, hemos remarcado los motivos por los cuales las instituciones políticas no pueden entenderse como meros contratos entre representantes y representados, sino como relaciones fiduciarias entre los agentes (cargos públicos) y su principal o beneficiario (ciudadanía soberana) a quien el primero debe lealtad. Respecto al segundo caso, el de la propiedad, hemos visto que el principal o pueblo soberano viene respaldado iusnaturalmente en cuanto a su derecho de apropiación, posesión y uso de la tierra para usos productivos y, en última instancia, para el "progreso de la sociedad". Pero también hemos alertado de que la noción del derecho natural empleada por el republicanismo jeffersoniano en ningún caso respalda el derecho de propiedad privada ni acaso su irrestricta acumulación, pues ésta es siempre "el regalo de la ley social" articulado mediante un pacto fiduciario.

A pesar de que creamos que un buen vallado hace siempre buenos vecinos, lo cierto es que la idea de que la propiedad tiene una "inherente obligación social no es tan controvertida en el derecho" (Lubens, 2007, 390). Esto nos debería hacer reparar en cuáles son los orígenes filosóficos, políticos y jurídicos que alimentan el principio de la "utilidad pública". Con ello descubriríamos, como sostiene William H. Simon (1991, 1412), que la lógica fiduciaria con que operó el republicanismo jeffersoniano "no es ni tan anómala ni tan inverosímil como usualmente sugiere la concepción dominante de la propiedad".

\section{Bibliografía}

Antieau, Ch. (1960), «Natural Rights and The Founding Fathers-The Virginians», Washington and Lee Law Review, 17, pp. 43-79.

Appleby, J. y Ball, T. (eds.). (1999), Thomas Jefferson. Political Writings, Cambridge: Cambridge University Press. 
Blackstone, W. (1897), Commentaries on the Laws of England, Philadelphia: West Publishing Company.

Callies, D. y Breemer, D. (2000), «The Right to Exclude Others from Private Property: A Fundamental Constitutional Right», Washington University Journal of Law \& Policy, 3, pp. 39-59.

Cicerón, M. T. (1948), De los Deberes, Morán, B. E. (trad. y ed.), México: Universidad Autónoma de México.

Clarry, D. (2014), «Fiduciary Ownership and Trusts in a Comparative Perspective», International and Comparative Law Quarterly, 63, 4, pp. 901-933.

Coghill, K., Sampford, Ch., y Smith, T. (eds.) (2012), Fiduciary duty and the atmospheric trust, Surrey: Ashgate Publishing Limited.

Congost, R. (2003), «Property Rights and Historical Analysis: What Rights? What History?», Past \& Present, 181, pp. 73-106.

Criddle, E. J. (2017), «Liberty in Loyalty: A Republican Theory of Fiduciary Law», Texas Law Review, 95, pp. 993-1060.

Criddle, E. (2014), «A Sacred Trust of Civilization: Fiduciary Foundations of International Law», en: Gold, A. y Miller, P. (eds.). Philosophical Foundations of Fiduciary Law, Oxford: Oxford University Press, pp. 404-422.

Criddle, E. y Fox-Decent, E. (2018), «Guardians of Legal Order. The Dual Commissions of Public Fiducia», en: Criddle, E.; Fox-Decent, E.; Gold, A.; Hui Kim, S. y Miller, P. (eds.): Fiduciary Government, Cambridge: Cambridge University Press, pp. 67-95.

Domènech, A. y Bertomeu, M. J. (2015), «Property, freedom and money: Modern Capitalism reassessed», European Journal of Social Theory, 19, 2, pp. 245-263.

Ely, J. W. (1992), The Guardian of Every Other Right. A Constitutional History of Property Rights, New York: Oxford University Press.

Epstein, R. (1985), Takings: Private Property and the Power of Eminent Domain, Cambridge: Harvard University Press.

Finn, P. (2012), «Public Trust and Fiduciary Relations», en: Coghill, K., Sampford, Ch., y Smith, T. (eds.), Fiduciary duty and the atmospheric trust, Surrey: Ashgate Publishing Limited, pp. 31-41.

Ford, P. (ed.), (1904-5), The Works of Thomas Jefferson, XII Vols., New York \& London: The Knickerbocker Press.

Fox-Decent, E. (2014), «Fiduciary Authority and the Service Conception», en: Gold, A. y Miller, P. (eds.). Philosophical Foundations of Fiduciary Law, Oxford: Oxford University Press, pp. 363-387.

Fox-Decent, E. (2011), Sovereignty's Promise: The State as Fiduciary, Oxford: Oxford University Press.

Fox-Decent, E. y Criddle, E. (2009), «The Fiduciary Constitution of Human Rights», Legal Theory, 15, pp. 301-336.

Frankel, T. (2011), Fiduciary Law, New York: Oxford University Press.

Godden, L., Grinlinton, D. y Taylor, P. (2011), «Communal Governance of Land and Resources as a Sustainable Property Institution», en: Grinlinton, D. y Taylor, P. (eds.), Property Rights and Sustainability, Leiden: Martinus Nijhoff Publishers, pp. 249-272. 
Hartz, L. (1955), The Liberal Tradition in America: An Interpretation of American Political Thought since the Revolution, New York: Harcourt Brace \& Co.

Jefferson, T. (1812), «The Proceedings of the Government of the United States in Maintaining the Public Right to the Beach of the Missisipi, Adjacent to New Orleans Against the Intrusion of Edward Livingston», The American Law Journal, V, Baltimore, New York.

Laitos, J. G. (1998), Law of Property Rights Protection: Limitations on Governmental Powers, New York: Wolters Kluwer.

Lee, A. (1775), An Appeal to the Justice and Interests of the People of Great Britain, in the Present Disputes with America, London: J. Almon.

Leib, E. J y Galoob, S. (2016), «Fiduciary Political Theory: A Critique», The Yale Law Journal, 125, pp. 1820-1878,

Leib, E.; Ponet, D. y Serota, M. (2014), «Mapping Public Fiduciary Relationships», en: Miller, P. y Gold, A. (eds.). Contract, Status, and Fiduciary Law, Oxford: Oxford University Press, pp. 388-403.

Lewis, C. (1985), «The Modern Conception of Ownership of Land», Acta Juridica, pp. 241266.

Lynd, S. (1969), Intellectual Origins of American Radicalism, London: Faber \& Faber.

Lubens, R. (2007), «The Social Obligation of Property Ownership», Arizona Journal of International \& Comparative Law, 24, 2, pp. 389-449.

MacGilvray, E. (2011), The Invention of Market Freedom, Cambridge: Cambridge University Press.

Madison, J. (2001), «The comparative means of influence of the federal and state governments», en: Carey, G. y McClellan, J. (eds.), The Federalist, Indianapolis: Liberty Fund.

Mansfield, H. (2003), «Liberty and Virtue in the American Founding», en: Berkowitz, P. (ed.), Never a Matter of Indifference: Sustaining Virtue in a Free Republic, Stanford: Hoover Press, pp. 3-28.

Markovits, D. (2014), «Sharing Ex Ante and Sharing Ex Post. The Non-Contractual Basis of Fiduciary Relations», en: Gold, A. y Miller, P. (eds.). Philosophical Foundations of Fiduciary Law, Oxford: Oxford University Press, pp. 209-224.

Miller P. (2018), «Fiduciary Representation», en: Criddle, E.; Fox-Decent, E.; Gold, A.; Hui Kim, S. y Miller, P. (eds.). Fiduciary Government, Cambridge: Cambridge University Press, pp. 21-48.

Miller, P. (2014), «The Fiduciary relationship», en: Gold, A. y Miller, P. (eds.). Philosophical Foundations of Fiduciary Law, Oxford: Oxford University Press, pp. 63-90.

Natelson, R. (2004), «The Constitution and the Public Trust», Buffalo Law Review, 52, pp. 1077-1178.

Purdy, J. y Fielding, K. (2007), «Sovereigns, Trustees, Guardians: Private-Law Concepts and the Limits of Legitimate State Power», Law and Contemporary Problems, 70, pp. $165-221$.

Rave, T. (2018), «Two Problems of Fiduciary Governance, en: Criddle, E.; Fox-Decent, E.; Gold, A., Hui Kim, S. y Miller, P. B. (eds.). Fiduciary Government, Cambridge: Cambridge University Press, pp. 49-66.

Rave, T. (2013), «Politicians as Fiduciaries», Harvard Law Review, 126, 3, pp. 671-739. 
Richard, C. (1994), The Founders and the Classics. Greece, Rome, and the American Enlightenment, Cambridge, Mass.: Harvard University Press.

Samet, I. (2014), «Fiduciary Loyalty as Kantian Virtue», en: Gold, A. y Miller, P. (eds.). Philosophical Foundations of Fiduciary Law, Oxford: Oxford University Press, pp. 125-140.

Sheehan, J. y Small, G. (2002), «Towards a Definition of Property Rights», Artículo presentado en la Pacific Rim Real Estate Society (PRRES) conference, Christchurch, New Zealand, Enero 2002.

Sherwin, E. (2016), «Formal Elements of Contract and Fiduciary Law», en: Miller, P. y Gold A. (eds.). Contract, Status, and Fiduciary Law, Oxford: Oxford University Press, pp. 167-181.

Simon, W. (1991), «Social-Republican Property», University of California Law Review, 38, 6, pp. 1335-1414.

Smith, G. (2016), «Firms and Fiduciaries», en: Miller, P. y Gold, A. (eds.). Contract, Status, and Fiduciary Law, Oxford: Oxford University Press, pp. 293-311.

Smith, L. (2016), «Contract, Consent, and Fiduciary Relationships», en: Miller, P. y Gold, A. (eds.). Contract, Status, and Fiduciary Law, Oxford: Oxford University Press, pp. 117-138.

Sitkoff, R. (2014), «An Economic Theory of Fiduciary Law», en: en: Gold, A. y Miller, P. (eds.). Philosophical Foundations on Fiduciary Law Oxford: Oxford University Press, pp. 197-208.

Vaitkus, S. (1991), How is society possible? Intersubjectivity and the fiduciary attitude as problems of the social group, Dordrecht: Kluwer Academic Publishers.

Whelan, F. (1980), «Property as Artificie: Hume and Blackstone», Nomos, 22, pp. 101-129.

Wood, G. (2011), «The Legacy of Rome in the American Revolution», en: Onuf, P. y Cole, N. (eds.). Thomas Jefferson, the Classical World, and the Early America, Virginia: University of Virginia Press, pp. 11-34. 